\title{
SENSORLESS STATOR FIELD ORIENTED-DIRECT TORQUE CONTROL WITH SVM FOR INDUCTION MOTOR DRIVE
}

\author{
Amjad Shumais ${ }^{1}$, Umamaheswari ${ }^{2}$
}

Abstract- This paper manages change of Direct Torque Control technique for induction motor (IM) drive. Since the primary drawbacks of the established DTC are high torque/flux ripples and current contortion, this paper embeds the space vector modulation keeping in mind the end goal to decrease the ripples by keeping up a consistent switching frequency. Furthermore, the fuzzy logic controllers will supplant the conventional proportional integral (PI) controllers for stator motion and torque direction and to guarantee a precise reference following and a strong reaction against various vulnerabilities, for example, outer aggravation and parameters variety. Moreover, a stator flux based Model Reference Adaptive System (SF-MRAS) is planned as a sensorless calculation for the estimation of rotor speed. This estimator can enhance the execution of the controlled framework by expanding its unwavering quality and diminishing the cost of the speed sensor. The worldwide control calculation has been explored by means of numerical reenactment and continuous experimentation utilizing Matlab/ Simulink with dSpace 1104 flag card.

Keywords - Induction Motor, Direct Torque Control (DTC), Space Vector Modulation (SVM), Fuzzy Logic Controller (FLC), Stator Flux Model reference adaptive system (SF-MRAS), dS 1104.

\section{INTRODUCTION}

The Direct Torque Control was proposed to supplant the field situated control (FOC) in drives space keeping in mind the end goal to accomplish a productive decoupled control of transition and electromagnetic torque. DTC offers a more straightforward plan, quicker reaction and low reliance to machine parameters than FOC. Besides, it doesn't require facilitates change or current direction [1]. Be that as it may, the fundamental issues of this technique are the abnormal state of swells in motion and electromagnetic torque which caused by the variable changing recurrence because of the discrete idea of the hysteresis comparators and look-into table for voltage vector determination [2].

The space vector adjustment (SVM) methodology has been talked about in writing to replaces the exchanging table by for voltage vector choice. By saving a steady exchanging recurrence, it can lessen essentially the motion and torque ripples [3]. In this specific situation, the SFOC based SVM-DTC will take our enthusiasm for this paper [4]. Lamentably, the utilization of PI controllers requires a particular information of control framework displaying. Moreover, PI controllers have a constrained execution while the nearness of unsettling influences and vulnerabilities and the determination of the increases isn't simple undertaking particularly by and by. Thus, the dynamic and strength of the worldwide framework can be influenced. Since the parameters distinguishing proof of the engine is for the most part done by established test tests, the estimation mistakes can't be evaded.

To conquer these disadvantages, various control strategies have been exhibited, for example, the variable structure sliding mode control (SMC), Model reference versatile control (MRAC) and simulated smart methods [5] [7]. The fuzzy logic controllers (FLC) has been fused with DTC system in a few works [5] [8]. They can offer great reaction and exact following without the learning of the control framework display. Hence, they will be utilized as a part of this work rather than the ordinary PI controllers for transition and torque direction

Well beyond, this paper expects to take out the mechanical sensor and supplant it by delicate sensorless algorithm with a specific end goal to diminish framework's cost and to enhance its unwavering quality [9]. A few works have been proposed for the reproduction of transition and rotor speed [10] [11]. The model reference versatile framework technique is broadly connected because of its effortlessness. Different MRAS structures have been displayed in writing [11] [12]. The rotor motion MRAS [13] is the most utilized among MRAS systems. This work shows an alternate MRAS estimator in view of stator motion demonstrates. The stator motion MRAS (SFMRAS) is more reasonable for stator documented situated SVMDTC control outline. It stays away from the rotor motion estimation step which picks up a reducer spectator intricacy.

Existing System: The space vector modulation (SVM) technique has been examined in writing to replaces the exchanging table by for voltage vector determination. By safeguarding a steady switching frequency, it can lessen fundamentally the motion and torque ripples. In this specific situation, the SFOC based SVM-DTC will take our enthusiasm for this paper Sadly, the utilization of PI controllers requires a particular information of control framework displaying. Besides, PI controllers have a restricted execution while the nearness of unsettling influences and vulnerabilities and the determination of

\footnotetext{
${ }^{1}$ P.G Scholar, Mahendra Engineering College, Namakkal (Dt)

${ }^{2}$ Professor \& Head, Dept. of EEE, Mahendra Engineering College, Namakkal(Dt)
} 
the additions isn't simple assignment particularly. Thusly, the dynamic and stability of the worldwide framework can be influenced. The parameters distinguishing proof of the motor is generally done

Disadvantage: The structure of stator motion based MRAS spectator comprising of two sections as the known rotor MRAS outline. A reference show and versatile model which contain the evaluated amount (rotor speed). An adjustment instrument to create it. The reference demonstrate called the voltage show. It is communicated by the reference voltages in the stationary casing and creates the reference transition esteems. In addition, the versatile model called likewise the present model. It is communicated by stator streams and the rotor speed.

Proposed System: An enhanced stator field situated DTC technique for enlistment engine drive utilizing fluffy rationale controllers and SVM calculation. At that point, an outline of stator transition MRAS spectator is displayed for speed estimation. The exhibited control technique is confirmed through the reproduction

\section{SFO SVM-DTC CONTROL STRATEGY}

A. Stator field situated IM Model: This methodology utilizes the dynamic model of the acceptance machine in the synchronous reference outline (d,q). The voltages model can be communicated in Eq (1) and (2) as

$$
\begin{aligned}
& v_{s d}=R s i_{s d}+\frac{d \psi s d}{d t}-\omega_{s} \psi s q \\
& v_{s q}=R_{s i} i_{s q}+\frac{d \psi s q}{d t}-\omega_{s} \psi_{s d} \\
& 0=v_{r d}=R_{r i} i_{r}+\frac{d \psi r d}{d t}-\left(\omega_{s}-\omega_{r}\right) \psi_{r q} \\
& 0=v_{r q}=R_{r i} i_{r q}+\frac{d \psi r q}{d t}+\left(\omega_{s}-\omega_{r}\right) \psi_{r d}
\end{aligned}
$$

B. SFOC Control outline: The stator field-introduction technique depends on the arrangement of motion vector with the immediate d-pivot and keeping up the quadratic parts of stator motion equivalent to zero:

$\psi s d=\psi s ; \psi s q=0$

It's widely realized that the d-pivot is the charging hub and q-hub is the torque hub [4]. The voltages conditions in synchronous edge can be communicated as:

$$
\begin{aligned}
& v_{s d}=R s i s d+\frac{d \psi_{s}}{d t} \\
& v_{s q}=R_{s i} i_{s q}+\omega_{s} \psi_{s}
\end{aligned}
$$

The electromagnetic torque is:

$$
T_{e}=P \psi_{s i} i_{s q}
$$

This calculation accomplishes stator transition and torque shut circle control and uses SVM for delivering the inverter's order signals. Generally, two PI controllers get the transition and torque errors as to deliver the (d, q) voltage segments (Vsd, Vsq) in a synchronous reference outline [6].

The reference voltages will be adjusted by the SVM unit to produce the inverter's charge states in the wake of changing them to stationary popularity $(\alpha, \beta)$. The exchanging recurrence of the space vector tweak is steady, as result, the torque and transition swells can be diminished fundamentally [4].

\section{FUZZY LOGIC CONTROL DESIGN}

In this segment, an isolated fluffy rationale controllers (FLCs) are intended to supplant the PI controllers and produce the reference's voltages in the synchronous casing. By and large, the fluffy rationale control is actualized in instances of nonlinear frameworks which have a level of vulnerability. This system is included that it doesn't require a correct demonstrating or recognizable proof. This makes FLC exceptionally appropriate for engine drive control [14]. The utilization of FLCs in SVM-DTC drive enhances its execution and ensures a decent task amid the relentless state, while keeping the first focal points of the DTC strategy [5]. The graph of the utilized FLC for transition and torque is delineated in Fig.1 


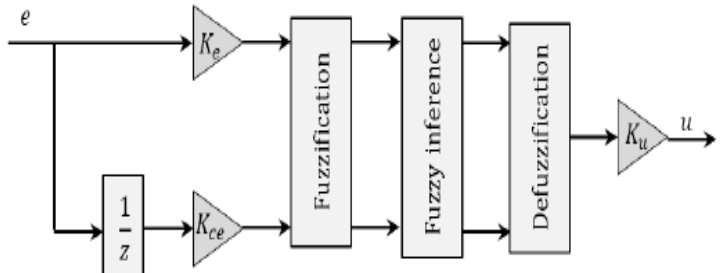

Fig.1 Diagram of the FLC.

For the most part, FLC is created from three fundamental process: fuzzification, semantic govern base and defuzzification. The following blunder and its opportunity subsidiary are considered as the information factors.

The transition size and torque mistakes are characterized by:

$e_{T e}=T_{e} *-T_{e}$
$e_{\psi s}=|\psi s *|-|\psi s|$

The elements Ke and Kce are the standardization coefficients which adjust the info factors and Ku is characterized to adjust the yield flag to the genuine yield run. There are seven factors for the info factors, characterized in the fluffy sets: PB (positive huge), PM (positive medium), PS (positive little), Z (zero), NS (negative little), NM (negative medium), and NB (negative huge). Also, additional factors are included the fluffy sets for the yield factors (PMB, PMS, NMB, NMS) to enhance the dynamic execution and acquire more refined yield. The lopsided triangles are chosen as the participation work in contributions to request to acquire high exactness for consistent state which is unique in relation to the traditional plan.

Figs. 2 and 3 display the enrollment elements of the data sources and the yields, individually.

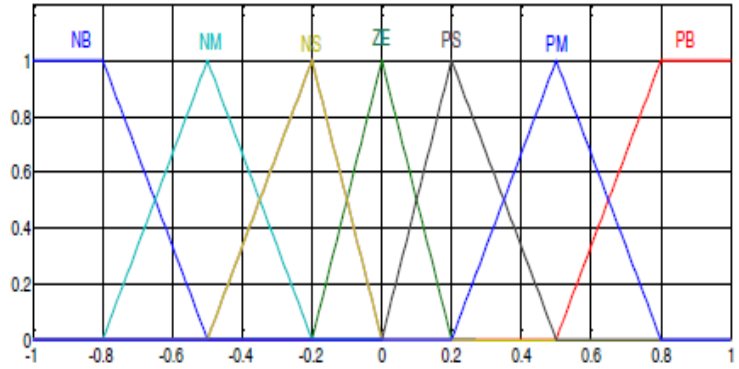

Fig.2. Input membership function.

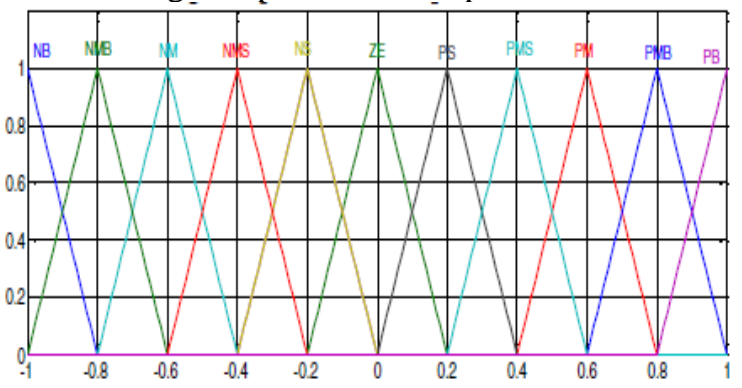

Fig.3. Output membership function.

Table.I shows the inference rule implemented in this paper, which is the important part of the FLC.

\begin{tabular}{|l|l|l|l|l|l|l|l|}
\hline e/ce & NB & NM & NS & ZE & PS & PM & PB \\
\hline NB & NB & NB & NBM & NM & NMS & NS & ZE \\
\hline NM & NB & NBM & NM & NMS & NS & ZE & PS \\
\hline NS & NBM & NM & NMS & NS & ZE & PS & PMS \\
\hline ZE & NM & NMS & NS & ZE & PS & PMS & PM \\
\hline PS & NMS & NS & ZE & PS & PMS & PM & PBM \\
\hline PM & NS & ZE & PS & PMS & PM & PBM & PB \\
\hline
\end{tabular}




\begin{tabular}{|l|l|l|l|l|l|l|l|}
\hline PB & ZE & PS & PMS & PM & PBM & PB & PB \\
\hline
\end{tabular}

TABLE. I Fuzzy Rules Base

\section{STATOR FLUX MRAS OBSERVER DESIGN}

The structure of stator motion based MRAS spectator comprising of two sections as the known rotor MRAS outline [15].A reference show and versatile model which contain the assessed amount (rotor speed). What's more, an adjustment system to deliver it. The reference display called the voltage demonstrate. It is communicated by the reference voltages in the stationary casing and produces the reference transition esteems. Besides, the versatile model called likewise the present model. It is communicated by stator streams and the rotor speed [13], [16]. The voltage and the present models are given in (8) and (9) separately:

$$
\begin{aligned}
& \psi_{s \alpha}=\int_{0}^{t}\left(V_{s \alpha}-R_{s \alpha} i_{s \alpha}\right) d t \\
& \psi_{s \beta}=\int_{0}^{t}\left(V_{s \beta}-R_{s \beta} i_{s \beta}\right) d t \\
& \hat{\psi}_{s \alpha}=\frac{L r}{R_{r}+L_{r} S}\left(\sigma L_{s} \hat{\psi}_{s \beta}+\frac{L_{s}}{L_{r}}\left(R_{r}+\sigma L_{r} s\right) i_{s \alpha}-\hat{\omega} \hat{\psi}_{s \beta}\right) \\
& \hat{\psi}_{s \beta}=\frac{L r}{R_{r}+L_{r} S}\left(\sigma L_{s} \hat{\psi}_{s \alpha}+\frac{L_{s}}{L_{r}}\left(R_{r}+\sigma L_{r} s\right) i_{s \beta}-\hat{\omega} \hat{\psi}_{s \alpha}\right)
\end{aligned}
$$

The error between the reference and the adaptive mode can be given:

$$
\begin{aligned}
& e_{\psi s \alpha}=\psi_{s \alpha}-\hat{\psi}_{s \alpha} \\
& e_{\psi s \beta}=\psi_{s \beta}-\hat{\psi}_{s \beta}
\end{aligned}
$$

The mechanism of adaptation produces the estimated rotor speed quantity via a PI controller basing on the error between the estimated fluxes through the voltage and the current models:

$$
\hat{\omega}=\left(K_{p}+\frac{K i}{s}\right) e_{\psi s}
$$

$\mathrm{Kp}$ and $\mathrm{Ki}$ are the proportional and the integral gains

$$
e_{\psi s}=\left(\psi_{s \beta} \hat{\psi} s \alpha-\left(i_{s \alpha} e_{\psi s \beta}-i_{s} \beta e_{\psi s \alpha}\right) \sigma L_{s}\right)
$$

The block diagram of MRAS estimator is presented in Fig.4.

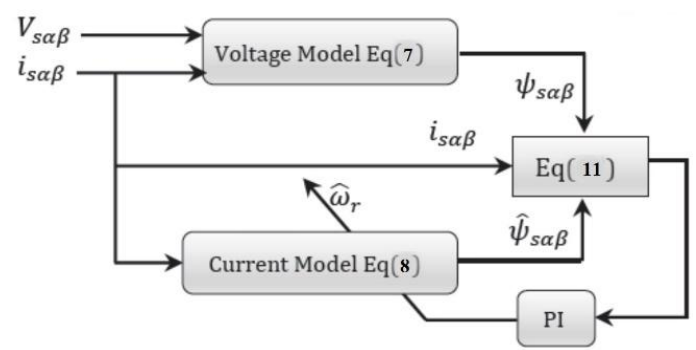

Fig.4. Diagram of SF-MRAS speed observer

The global control scheme of SFO SVM-DTC with fuzzy logic controllers and SF-MRAS observer is presented in Fig.5 


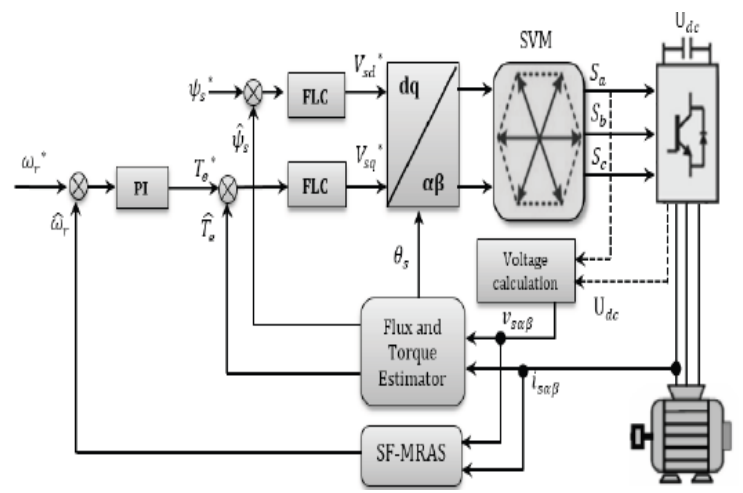

Fig.5 Diagram of SFO SVM-DTC with fuzzy logic controllers and SFMRAS speed observer.

\section{SENSORLESS STRATOGY}

This paper aims to eliminate the mechanical sensor and replace it by soft sensor less algorithm in order to decrease system's cost and to improve its reliability.

Several works have been proposed for the reconstruction of flux and rotor speed. The model reference adaptive system method is widely applied due to its simplicity. Various MRAS structures have been presented in literature. The rotor flux MRAS is the most used among MRAS strategies. This work presents a different MRAS estimator based on stator flux model. The stator flux MRAS (SFMRAS) is more suitable for stator filed oriented SVM-DTC control design. It avoids the rotor flux estimation step which gains a reducer observer complexity.

Rotor speed estimation under variable speed reference in low regions:

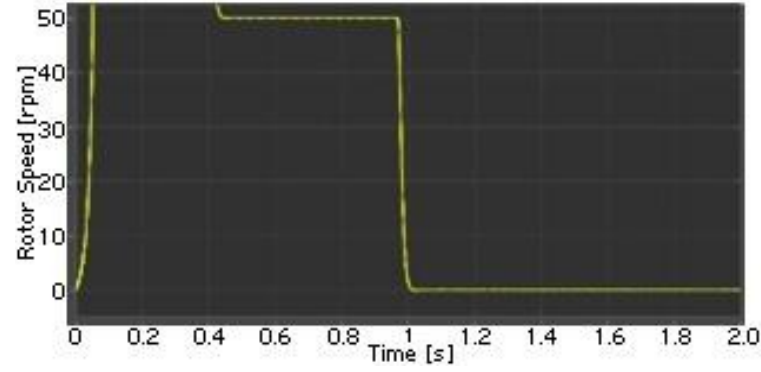

Fig.6 Rotor speed estimation under variable speed reference in low region

Presents the low speed operation test, it illustrates the speed variation from zero to 50 and $120 \mathrm{rpm}$, the MRAS observer show good estimation accuracy even at zero speeds, the real and estimated speed show a perfect superposition, the error converges always to zero. This reflect the good performance and robustness of the sensorless strategy in various speed environments.

Speed estimation error:

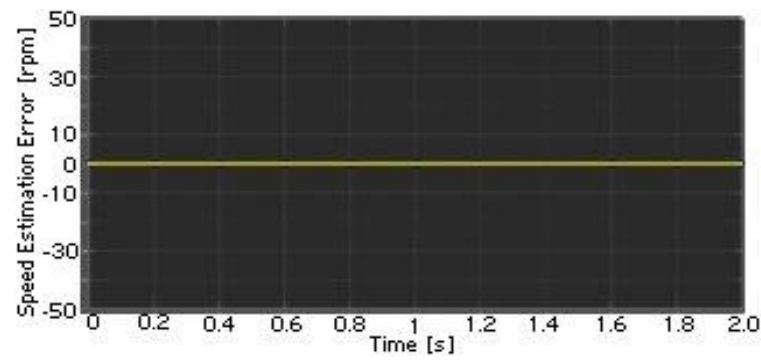

Fig.7 Speed estimation error

The figure shows the real and estimated speeds. The estimation error is presented; the speed quantities have a good superposition with small overshoot, while the error converges quickly to zero.

Electromagnetic torque and stator phase current during starting up and sense reversing: 


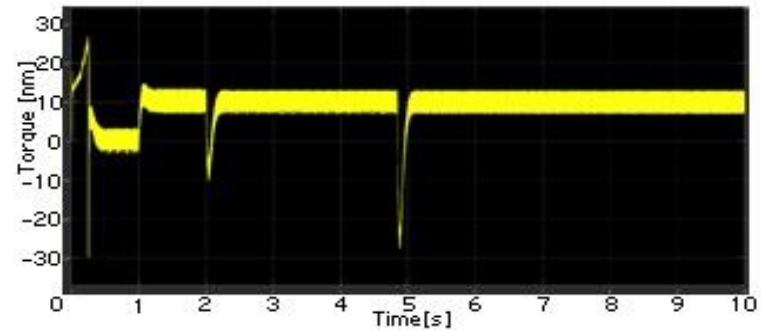

Fig.8 Electromagnetic torque during start up

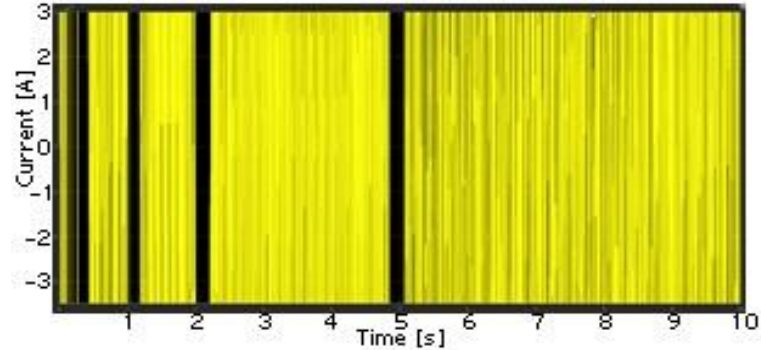

Fig.9 Stator phase current during start up

Shows the torque and stator phase current during the starting up state and sense reversal. Then Fig. 8 and 9 shows the load application test. It can be noticed that both of torque and current present a fast response with low ripples and harmonics and both tests.

Speed estimation error in low regions:

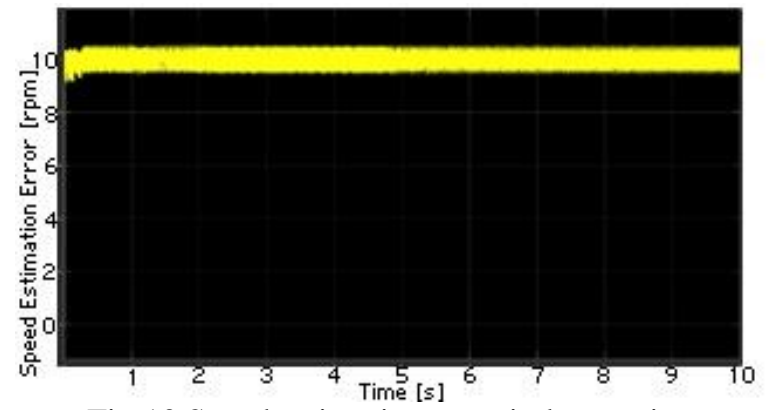

Fig.10 Speed estimation error in low region

Electromagnetic torque and stator phase current with load introduction:

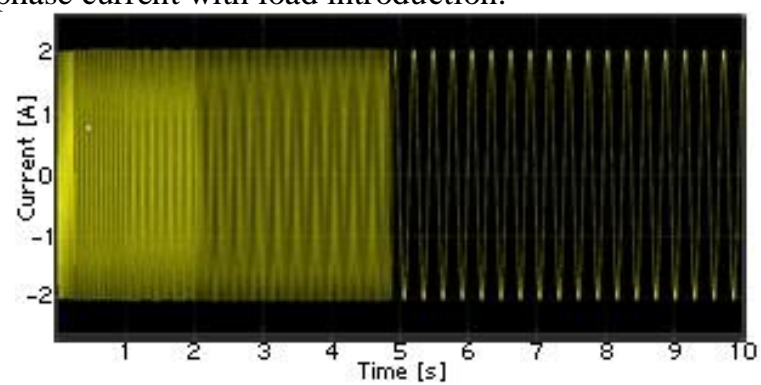

Fig.11 Stator phase current with load induction

Shows the load application test. It can be noticed that both of torque and current present a fast response with low ripples and harmonics and both tests.

Next, illustrate the flux components in stationary and synchronous frames, they show good dynamic sinusoid waveform while the reversing. The direct flux component (i.e. stator flux magnitude) is featured by accurate tracking, fast and robust response and low ripples due to the combination of SVM with FLCs controllers.

\section{CONCLUSION}

This paper manages enhanced stator documented SVM-DTC in view of fluffy rationale controllers and speed MRAS eyewitness for enlistment engine drive. The (d, q) segments of reference voltages have been created in light of decoupled FLCs controllers for stator motion and electromagnetic torque control. 
This calculation has been intended to conquer distinctive disadvantages and issues worried to DTC. The utilization of SVM give numerous favorable circumstances, and they have been checked by reproduction and experimentation, for example, great reacting, decreased swells, low sounds and great waveform of stator stage current, and steady exchanging recurrence. To acquire streamlined exhibitions, the FLCs which don't require the information of the scientific model have supplanted the customary PI controllers. They have a quicker unique, precise following and vigor against outer unsettling influence. Well beyond, the MRAS eyewitness has a precise estimation in various speed areas which enhance the unwavering quality by the get rid of the utilization of speed sensor. For the most part, the addition of smart controllers and sensorless eyewitnesses can get all the more superior exhibitions

\section{REFERENCES}

[1] D. Casadei, F. Profumo, G. Serra, and A. Tani, "FOC and DTC:Two viable schemes for induction motors torque control," IEEE Trans. Power Electron., vol. 17, no. 5, pp. 779-787, 2002.

[2] I. M. Alsofyani and N. R. N. Idris, "Simple Flux Regulation for Improving State Estimation at Very Low and Zero Speed of a Speed Sensorless Direct Torque Control of an Induction Motor,” IEEE Trans. Power Electron., vol. 31, no. 4, pp. 3027-3035, Apr. 2016.

[3] T. G. Habetler, F. Profumo, M. Pastorelli, and L. M. Tolbert, "Sensorless SVM-Direct Torque Control for Induction Motor Drive," Ind. Appl. IEEE Trans., vol. 28, no. 5, pp. 1045-1053, 1992.

[4] A. Ammar, A. Bourek, and A. Benakcha, "Sensorless SVM-Direct Torque Control for Induction Motor Drive Using Sliding Mode Observers," J. Control. Autom. Electr. Syst., vol. 28, no. 2, pp. 189- 202, Apr. 2017.

[5] H. Saberi, M. Feyzi, M. B. B. Sharifian, and M. Sabahi, "Improved sensorless direct torque control method using adaptive flux observer,'IET Power Electron., vol. 7, no. 7, pp. 1675-1684, Jul. 2014.

[6] A. Ammar, A. Benakcha, and A. Bourek, "Adaptive MRAC-based direct torque control with SVM for sensorless induction motor using adaptive observer," Int. J. Adv. Manuf. Technol., Dec. 2016.

[7] A. Ammar, A. Bourek, and A. Benakcha, "Nonlinear SVM-DTC for induction motor drive using input-output feedback linearization and high order sliding mode control," ISA Trans., vol. 67, pp. 428-442, Mar. 2017.

[8] V. N. N, A. Panda, and S. P. Singh, “A Three-Level Fuzzy-2 DTC of Induction Motor Drive Using SVPWM,” IEEE Trans. Ind.Electron., vol. 63, no. 3, pp. 1467-1479, Mar. 2016.

[9] O. Barambones and P. Alkorta, "Position Control of the Induction Motor Using an Adaptive Sliding-Mode Controller and Observers," IEEE Trans. Ind. Electron., vol. 61, no. 12, pp. 6556-6565, Dec. 2014.

[10] T. Ameid, A. Menacer, H. Talhaoui, I. Harzelli, and A. Ammar, "Simulation and real-time implementation of sensorless field oriented control of induction motor at healthy state using rotor cage model and EKF," in 2016 8th International Conference on Modelling, Identification and Control (ICMIC), 2016, pp. 695-700.

[11] A. K. Chattopadhyay, S. Das, and R. Kumar, "Comparative assessment of two different model reference adaptive system schemes for speed-sensorless control of induction motor drives," IET Electr. Power Appl., vol. 10, no. 2, pp. 141-154, Feb. 2016.

[12] A. N. Smith, S. M. Gadoue, and J. W. Finch, "Improved rotor flux estimation at low speeds for torque MRAS-based sensorless induction motor drives," IEEE Trans. Energy Convers., vol. 31, no.1, pp. 270-282, 2016.

[13] T. Ohtani, N. Takada, and K. Tanaka, "Vector control of induction motor'without shaft encoder," in Conf. Rec. 1989 IEEE IAS Ann. Mtg., pp. 500507.

[14] Yongchang Zhang, Jianguo Zhu, Zhengming Zhao, Wei Xu, and D. G. Dorrell, “An Improved Direct Torque Control for Three-Level Inverter-Fed Induction Motor Sensorless Drive," IEEE Trans. Power Electron., vol. 27, no. 3, pp. 1502-1513, Mar. 2012.

[15] Y. A. Zorgani, Y. Koubaa, and M. Boussak, "MRAS state estimator for speed sensorless ISFOC induction motor drives with Luenberger load torque estimation," ISA Trans., vol. 61, pp. 308-317, Mar. 2016.

[16] S. M. Gadoue, D. Giaouris, and J. W. Finch, "MRAS Sensorless Vector Control of an Induction Motor Using New Sliding-Mode and Fuzzy-Logic Adaptation Mechanisms," IEEE Trans. Energy Convers., vol. 25, no. 2, pp. 394-402, 2010 